\title{
LEITURA LITERÁRIA NAS SÉRIES INICIAIS DO ENSINO FUNDAMENTAL: SUBJETIVIDADE NA FORMAÇÃO DO LEITOR
}

\author{
$\operatorname{Prof}^{\mathrm{a}}$. Dra ${ }^{\mathrm{a}}$. Sheila Oliveira Lima (Docente Letras Vernáculas e Clássicas, PPGEL, \\ PROFLETRAS/UEL) \\ Angela Rodrigues da Silva (Graduanda Letras Vernáculas e Clássicas/UEL) \\ Henrique Furtado de Melo (Mestrando PPGL/UEL)
}

\section{RESUMO}

O projeto "Leitura literária no Ensino Fundamental - ciclo 1: concepções e práticas" realizou, entre os anos de 2012 e 2015, análises das propostas de leitura de textos literários presentes em 10 coleções didáticas de língua portuguesa do Ensino Fundamental 1. Constatou, nesse percurso, a ausência de um trabalho que considerasse a subjetividade do leitor como fator para a sua vinculação com a leitura. A partir de propostas trazidas pelos livros didáticos (LD) analisados, foram criadas novas atividades que trabalharam a leitura a partir de uma abordagem criativa, ressignificando, para o leitor em formação, o seu lugar de protagonismo na atividade leitora. Foram realizadas três propostas distintas com cada um dos gêneros consagrados na literatura (narrativa, teatro e poesia) e aplicadas com crianças do $1^{\circ}$ e do $2^{\circ}$ anos. Nesta comunicação, apresentaremos nossas análises das atividades dos LD, as propostas aplicadas e os resultados das aplicações.

Palavras-chave: Leitura literária; Livro didático; subjetividade.

Os estudos relativos aos aspectos cognitivos da leitura avançaram muito nos últimos anos. As reflexões em torno dos processos ascendente e descendente de percepção e assimilação da informação foram fundamentais para a compreensão de que a leitura não se esgota nem principia no momento do encontro dos olhos com as letras. $\mathrm{O}$ entendimento de que os conhecimentos prévios e a memória, ao lado de capacidades como a inferência, são elementos fundamentais no processo de leitura promoveu um grande avanço para a proposição de novas estratégias e metodologias de ensino da leitura.

Entretanto, deve-se admitir que, mesmo com toda a complexidade dos processos cognitivos que viabilizam a leitura, ainda há outras instâncias que ensejam sua realização. Interessa-nos, neste artigo, abordar os aspectos relativos ao afeto, às possibilidades de subjetivação decorrentes do ato da leitura, sobretudo do texto literário. Nessa esteira, a preocupação principal deste estudo é refletir a respeito dos processos de subjetivação na formação do leitor a partir da experiência com a leitura literária.

A Análise do Discurso, em sua concepção de sujeito e de subjetividade, observa que a leitura não é um processo apenas de ordem cognitiva, mas discursiva. Trata-se de uma produção realizada pelos leitores na interlocução promovida pelo contato entre texto e leitor. Nesse sentido, Indurski (2011, p.147) afirma que a leitura resulta de um encontro entre sujeitos ideologicamente constituídos, "em que o leitor se constitui como efeito-leitor". Numa situação de maior submissão ao texto, o leitor se posiciona como 


\section{SEMINÁRIO DE PESQUISA EM CIÊNCIAS HUMANAS - SEPECH \\ Humanidades, Estado e desafios didático-científicos \\ Londrina, 27 a 29 de julho de 2016}

"função-leitor", enquanto que, ao se inscrever "em outra "Formatação Discursiva", emerge como sujeito-leitor".

Além das situações constituídas a partir do posicionamento ideológico, discursivamente demarcado, entrevemos, sobretudo na leitura realizada por crianças em início de formação, aspectos de ordem afetiva, emocional, em última análise, psíquica. Esse aspecto foi amplamente debatido pela Estética da Recepção e pela Teoria do Efeito, na perspectiva de identificação de características do leitor como determinantes do próprio fazer literário.

O sujeito que emerge no ato da leitura - seja pela identificação com temas, personagens, enunciados poéticos ou por qualquer outro fator de ordem simbólica deve ser considerado em sua dimensão mais complexa e profunda, naquilo que entendemos que as teorias relativas ao texto ou ao sujeito em sua dimensão políticoideólogica não têm condições de mapear. Optamos, portanto, na constatação dessa lacuna, pelas linhas de reflexão com base na psicanálise freudo-lacaniana.

A instauração de um eu, segundo a psicanálise freudiana, tem seu princípio no momento da separação do bebê em relação à sua mãe. Essa separação, entretanto, só se estabelece de modo definitivo a partir do momento em que a criança se reconhece separada da mãe, quando, então percebe-a como um outro e, assim, referencia-se pela falta, pela incompletude. (FREUD, 2003)

Nessa esteira, Lacan traça seu conceito de sujeito a partir da instauração da linguagem, pelo "não" que ela estabelece. Isto é, a constituição do sujeito se realiza pela interdição que a linguagem impõe no contato com o Outro. $\mathrm{O}$ "não" que distingue o bebê e sua mãe, que interdita a plenitude de um "eu", é justamente o que garante a sua existência subjetiva e que instaura um processo infinito de busca pela completude perdida para sempre.

Deste modo, em sua jornada, o sujeito se depara com outros significantes, no espaço simbólico das interações enunciativas. Na leitura, por exemplo, encontra novas representações de si e do seu desejo, ao que podemos chamar de um processo de identificação.

Tendo em vista esse intrincado universo de construção simbólica, parece-nos fundamental refletir sobre a leitura nos espaços escolares como uma tarefa de alta responsabilidade e de complexidade ainda a ser explorada.

Em primeiro lugar, é preciso destacar a necessidade de reconher o processo criativo implicado na leitura. Uma vez que se trata de um fenômeno atravessado pela subjetividade, o traço criativo, em certo sentido, produtivo, é fundamental.

Ainda no que tange à reflexão psicanalítica, Winnicott (1975) observa a relação indissociável entre a subjetvidade e a criatividade. Para o psicanalista inglês, o ato criativo estabelecido na brincadeira das crianças se realiza num espaço por ele chamado transicional. Nesse espaço de intermediação entre o eu e o outro é que se estabelece, através do ato criativo, o reconhecimento de um outro e da própria constituição do eu. Nesse sentido, a subjetividade só se constitui a partir da atividade criativa no espaço trasicional.

Nessa mesma direção, Petit (2007) compreende a leitura como espaço transicional, território onde, mesmo em situações de extrema carência de afeto, torna-se possível a vivência criativa e a expressão da subjetividade. 


\section{SEMINÁRIO DE PESQUISA EM CIÊNCIAS HUMANAS - SEPECH \\ Humanidades, Estado e desafios didático-científicos \\ Londrina, 27 a 29 de julho de 2016}

Barthes (2004), já em 1975, viu na leitura uma atividade que se define pelo transbordamento criativo do leitor. Para o teórico, mais do que codificação, trata-se de uma sobrecodificação, ato, por definição, criativo e de manutenção da subjetividade.

Em se tratando de ato criativo, dentro da perspectiva winnicottiana, pode-se referendar que a leitura tenha condições de instituir-se também como jogo, brincadeira de faz-de-conta, de assunção de papéis diversos, de deslocamento das posições mais arraigadas para se experimentarem tantas outras, de outros. Nesse sentido, enquanto ato criativo e tão vinculado ao brincar, a leitura do texto literário demanda parcerias, espaços de compartilhamento, reais ou virtuais.

Colomer (2007) atenta para o fato de que a formação do leitor demanda compartilhamentos: do entusiasmo, da construção do significado e das conexões que os livros estabelecem entre si. A necessidade de tais compartilhamentos reforça a vinculação entre a leitura e o processo de constituição da subjetividade, na medida em que, por meio do encontro e do reconhecimento do outro - suas leituras, criações, interpretações e sobrecodificações -, o sujeito-leitor prossegue na constituição de si.

O leitor iniciante melhor estabelecerá seus vínculos com a leitura, se enlaçado pelo complexo de encontros com o outro e consigo mesmo, situação em que a literatura é espaço privilegiado para a realização autêntica de tais eventos.

\section{O PROJETO}

Amparado por tais reflexões a respeito do caráter criativo da leitura literária e da necessidade de o leitor em fase inicial poder melhor estabelecer seus vínculos com a atividade leitora por meio do encontro com a literatura, o projeto "Leitura literária no Ensino Fundamental - Ciclo 1: concepções e práticas" visualizou duas frentes princiapais de atuação.

A primeira delas foi a avaliação de propostas de leitura do texto literário e a sua inserção na formação do leitor das séries iniciais do Ensino Fundamental. Ao longo dos anos de 2013 e 2014, foram avaliadas atividades com texto literário nos dois primeiros volumes de dez coleções de livros didáticos de Língua Portuguesa do Ciclo 1 do Ensino Fundamental.

Ao final do processo, os resultados das análises apontaram para uma equivalência entre os textos da esfera do cotidiano e os da literária em ambas as séries. Porém, o aproveitamento dos textos da esfera literária mostrou uma forte tendência ao uso dos mesmos como pretexto para atividades de alfabetização e gramática $(41 \%$ no primeiro ano, 29,5\% no segundo ano), caracterização de gênero (6,1\% e 17,6\%), produção textual $(5,5 \%$ e $9,1 \%)$ e reflexão temática $(5 \%$ e $12,5 \%)$. Em oposição a esse quadro, tem-se a abordagem que empreende a leitura propriamente dita (34\% e $22,7 \%$ ) e a apreensão do texto enquanto literatura $(8,4 \%$ e $8,5 \%)$.

Vale ressaltar que esses percentuais das atividades de leitura correspondem apenas ao recorte de textos da esfera literária. No âmbito da totalidade dos textos dos livros analisados, somadas as esferas do cotidiano e literária, os percentuais relativos à atividade de leitura caem para $\mathbf{2 , 3 7 \%}$, nos volumes do primeiro ano, e $\mathbf{2 , 6 \%}$, nos do segundo ano.

Outro aspecto fundamental observado nas investigações refere-se ao tipo de atividade proposto para as leituras literárias. Os questionários com respostas 


\section{SEMINÁRIO DE PESQUISA EM CIÊNCIAS HUMANAS - SEPECH \\ Humanidades, Estado e desafios didático-científicos \\ Londrina, 27 a 29 de julho de 2016}

dissertativas ou de múltipla escolha correspondem a 64\% das atividades de leitura literária nos livros do $1^{\circ}$ ano e a $76 \%$ nos do $2^{\circ}$ ano. As atividades que não se conformam a tal perfil distribuem-se, tanto para uma série quanto para a outra, em propostas de desenho ou comentários orais livres.

Tanto os questionários quanto as propostas de desenhos se configuram a partir do isolamento da criança com seu material, não havendo a perspectiva de trocas, compartilhamentos, encontros com outras interpretações possíveis. Também as respostas dadas aos questionários em nada contribuem para uma apropriação criativa dos textos, uma vez que traçam olhares unidirecionados, com expectativa de resposta única.

Deste modo, consideramos que, em sua maioria, as atividades de leitura de textos literários contidas nos livros didáticos analisados ao longo da pesquisa não contemplam minimamente os pressupostos que destacamos acima a respeito da relação entre leitura, criatividade e subjetividade. Tampouco têm condições de estabelecer os princípios fundamentais apontados por Colomer para que a leitura se instaure como atividade fundada pelos compartilhamentos.

\section{NOSSAS PROPOSTAS}

Diante de tal situação, foram propostas três atividades baseadas nos estudos teóricos antes realizados e com o objetivo de vislumbrar as possibilidades de efetuar leitura literária com alunos em estágio inicial de alfabetização e pouca experiência leitora.

Também foram consideradas na produção das propostas de leitura literária os elementos que se mostraram essenciais na reflexão a respeito dos entraves para a formação do leitor evidenciados nos LDs. Deste modo, procurou-se: (a) criar atividades com os três gêneros basilares da literatura; (b) apresentar textos de autores reconhecidos pela crítica literária; (c) evitar o uso exclusivo do instrumento questionário; (d) proporcionar a leitura literária por meio do compartilhamento entre os alunos; (e) objetivar a sobrecodificação e a leitura criativa como procedimentos da leitura literária; (f) lidar com os aspectos temáticos e estéticos do texto literário.

Foram produzidas três propostas de leitura literária com atividade de compartilhamento, sobrecodificação e leitura criativa.

Duas das propostas criadas pelo grupo de pesquisadores foram executadas no Colégio de Aplicação da UEL, com alunos de $1^{\circ}$ e $2^{\circ}$ anos do período vespertino, e uma numa escola privada de São Paulo, sendo o principal objetivo das aplicações avaliar a eficácia da atividade enquanto promotora da leitura literária, tendo em vista os pressupostos teóricos elencados ao longo do projeto.

\section{NARRATIVA}

O texto "A princesa e o grão de ervilha" foi o propulsor da atividade narrativa. A história gira em torno de uma princesa que, certo dia, aparece na casa de um príncipe necessitando abrigo. Tanto o príncipe quanto a rainha e o rei, desconfiam da princesa por sua aparência física. Depois de uma noite de sono, os moradores descobrem que 


\section{SEMINÁRIO DE PESQUISA EM CIÊNCIAS HUMANAS - SEPECH \\ Humanidades, Estado e desafios didático-científicos \\ Londrina, 27 a 29 de julho de 2016}

aquela era realmente uma verdadeira princesa, pelo fato de ter sido capaz de sentir um grão de ervilha - colocado intencionalmente pela rainha - debaixo dos vinte colchões sobre os quais foi posta para dormir. O texto conclui com duas afirmações: a princesa era autência e a narrativa era, realmente, uma verdadeira história de princesas.

A atividade tinha como motivação promover a desconstrução de ideias préconcebidas que geralmente fazem parte das narrativas tradicionais, bem como apresentar novas formas de visualizar a história, possibilitando questionamentos individuais e coletivos sobre questões hierárquicas, sociais e de valores presentes no texto. Assim, buscava proporcionar às crianças a fuga de respostas prontas, para isso envolvendo maior subjetividade e possibilitando a desconstrução de conceitos a partir de suas próprias reflexões.

A atividade de leitura foi implementada no Colégio Aplicação da UEL. Contou com uma turma de primeiro ano e fez uso de duas aulas em dias diferentes para sua realização. Em ambas as aulas o espaço usado foi a biblioteca. Nessas aulas, foi realizada a troca de livros presente na rotina escolar dos alunos e logo em seguida as atividades se iniciaram.

A turmas tinha 25 alunos, de seis e sete anos. Inicialmente, a atividade seria realizada em apenas uma aula, mas observou-se a necessidade de concluí-la em outro dia. A turma ficou dividida em grupos de cinco e seis alunos.

Em ambas as aulas, houve muito interesse dos alunos, que responderam positivamente no que diz respeito à sobrecodificação, intertextualidade, analogias propostas, como também à leitura criativa.

Um dos problemas que impossibilitaram maior êxito na realização da atividade foi a constituição do horário das aulas. As crianças fizeram a troca de livros antes da aplicação da atividade e, antes mesmo de a aula terminar, estavam agitadas pois logo em seguida teriam o recreio. Além disso, a necessidade de aplicar a atividade em duas aulas - devido à escassez do tempo após a troca de livros - fez com que fosse necessária a retomada da história e dos debates já realizados anteriormente, na aula anterior. Embora tais fatores tenham influenciado negativamente, a atividade obteve êxito, pois alcançou seus principais objetivos. As crianças apresentaram questionamentos sobre diversos conceitos que faziam parte da narrativa, como as características fisicas de uma princesa, incitando-as a pensar se uma princesa tinha que sempre aparecer aliada a um padrão estético específico. Formou-se, também, um livre debate acerca das questões hierárquicas e de sucessão ao poder, concernentes ao contexto da narrativa lida.

Houve, durante todo o tempo da atividade, o compartilhamento de ideias e de repertórios entre os alunos. À medida em que o diálogo foi se estendendo, os questionamentos não seguiam mais um roteiro a ser aplicado e os alunos, em geral, estavam presentes e se inseriam na narrativa.

Uma discussão que chamou a atenção dos pesquisadores foi a fala de algumas crianças que buscavam identificar-se com a princesa da história. Para isso, em seus argumentos, desfaziam-se do imaginário tradicional da princesa frágil, rica, delicada e assumiam seu lugar, justificando a autenticidade de tal deslocamento no simples fato de decidirem que eram elas também princesas verdadeiras. 


\section{SEMINÁRIO DE PESQUISA EM CIÊNCIAS HUMANAS - SEPECH \\ Humanidades, Estado e desafios didático-científicos \\ Londrina, 27 a 29 de julho de 2016}

\section{TEATRO}

Constatando a ausência quase completa do gênero teatral nos livros didáticos do Ciclo 1 do Ensino Fundamental, considerou-se relevante a sua abordagem nas atividades de leitura criadas. Assim, optou-se por trabalhar um trecho da peça Chapeuzinho Vermelho, de Maria Clara Machado.

A atividade conta com uma leitura inicial para reconhecimento do texto, seguida de uma proposta de vivência da peça por meio da sua representação por parte dos alunos. Como se trata de um excerto que corresponde à cena de abertura de Chapeuzinho Vermelho, o trecho finaliza com um momento de suspensão da narrativa, a partir do qual é deflagrada toda a aventura, trecho ao qual, em nossa atividade, os alunos não tiveram acesso. Sendo assim, a partir do suspense acionado pelo excerto, foi proposta, aos alunos, a criação de breve continuidade e conclusão do enredo, bem como a sua encenação.

Para viabilizar a atividade de leitura e encenação, foi sugerido na proposta que a classe fosse organizada em grupos de quatro alunos, sendo que três deles assumiriam o papel das personagens e um se encarregaria da direção das cenas.

A brincadeira de se colocar no lugar da Chapeuzinho Vermelho, da sua mãe e do caçador e mesmo de se posicionar como o diretor-organizador da representação, enseja que a criança-leitora assuma o lugar de autoria, na medida em que lhe é autorizada a criação das personagens, dos cenários, das tensões que o texto apenas indicia. Promovese, portanto, a leitura criativa e o diálogo autêntico entre obra e leitor.

A atividade foi realizada numa escola privada, na região oeste da cidade de São Paulo, com alunos do $2^{\circ}$ ano. A classe era constiuída por nove alunos entre 7 e 8 anos de idade.

A professora procurou seguir todos os passos da proposta até o ponto da representação para a sala. Para tanto, dispôs de duas aulas seguidas de cinquenta minutos cada. Entretanto, procurando realizar a atividade com mais qualidade, segmentou-a em dois momentos: o da leitura e representação e o da criação do final e nova representação.

Segundo a professora, os alunos se engajaram de imediato à atividade. Leram o texto com certa facilidade, compreenderam rapidamente as etapas a serem realizadas e, mais importante, mostraram-se vivamente interessados em efetivar a representação da cena. Vale dizer que não se tratava da primeira experiência dos alunos com a encenação, visto que, no $1^{\circ}$ ano da escola, o teatro é uma disciplina obrigatória, embora não lide com a notação do texto nem com a leitura de peças. Entretanto, não é desprezível a experiência e o convívio com o gênero, mesmo que restrito à oralidade, como elemento constitutivo da formação do leitor, sobretudo de literatura e, ainda, do leitor de literatura que se permite subjetivar o lido, que vivencia uma experiência criativa ao ler literatura.

\section{POESIA}

A partir do poema "Sobrenome" de José Paulo Paes, buscamos proporcionar uma atividade de leitura que empenhasse os alunos num movimento de questionar-se 


\section{SEMINÁRIO DE PESQUISA EM CIÊNCIAS HUMANAS - SEPECH \\ Humanidades, Estado e desafios didático-científicos \\ Londrina, 27 a 29 de julho de 2016}

acerca das semelhanças e diferenças entre eles, bem como pensar em si mesmos como multiplicidade análoga à construção da figura central do poema, o Frankenstein.

A aplicação da atividade no segundo ano deu-se na apinhada biblioteca da escola. À atividade com os vinte alunos precedeu o hino de Londrina, o que resultou em alunos um pouco agitados. Outro ponto importante é que 10 minutos do tempo destinado à atividade foram gastos com uma troca de livros organizada pela bibliotecária.

Ao longo da atividade, as crianças, sentadas ao redor de quatro mesas, foram demonstrando interesse progressivo na participação, apesar da disposição espacial dificultar os planos. O ideal teria sido que os alunos estivessem em círculo, para que pudessem olhar uns para os outros e ouvir o que os colegas tinham a dizer.

Começamos com a leitura em voz alta do poema, buscando, em seguida, resgatar as memórias dos alunos relativas ao Frankenstein, como forma de explorar a intertextualidade com o romance de Mary Shelley e introduzir a questão identitária a partir da corporalidade, da mistura de pedaços e da dificuldade de se identificar um ser único feito a partir de uma multiplicidade de seres anteriores.

$\mathrm{Na}$ medida em que seguimos com as discussões, as crianças foram demonstrando interesse em participar, e começaram a levar as questões identitárias para seus próprios corpos e, posteriormente, para gestos, sentimentos e gostos em comum ou diferentes em relação aos colegas e parentes. Percebemos que o poema e a condução que escolhemos seguiu num caminho satisfatório, resultando em muitas questões e reflexões a respeito da relação eu-outro. No entanto devemos ponderar que uma série de dificuldades tornaram a atividade menos criativa e efetiva do que poderia ter sido.

O tempo de aula foi aspecto crucial para nossa análise. Notamos como, apesar de não haver sinal sonoro ao final de cada aula, as crianças pareceram já condicionadas ao esquema engradado de disciplinas. $\mathrm{O}$ andamento da leitura incitara curiosidade $\mathrm{e}$ interesse, que teriam sido melhor aproveitados num tempo maior de aula e numa disposição espacial melhor.

Já na aplicação realizada com o primeiro ano, os alunos estavam em sala de aula com a presença da professora regente, que durante toda a realização da atividade, atuava na manutenção da disciplina das crianças, sempre que julgava necessário.

A partir da solicitação da professora de sala, foi permitido aos alunos fazerem uma primeira leitura exploratória do poema, o que tomou um grande tempo da aula. Vários dos alunos faziam a leitura sonorizada, o que causava um burburinho. Terminada essa fase de reconhecimento do texto, questionou-se o que haviam compreendido e se tinham dúvidas sobre o poema. Várias crianças tinham dúvida a respeito da palavra "Frankenstein", presente nas primeiras linhas do texto. A partir dessa dúvida, que, na verdade referia-se à precariedade da decodificação alfabética aliada ao desconhecimento de uma ortografia estrangeira, deu-se início ao debate a respeito da figura de Frankenstein, motivadora do poema a respeito da fragmentação dos indivíduos e da dificuldade de reconhecer a própria identidade.

Vários alunos conheciam bases da narrativa do clássico de Mary Shelley, o que facilitou o diálogo a respeito da construção de um homem a partir de outros homens, de onde foi possível conduzir a discussão a respeito da constituição da subjetividade a partir do encontro e da reprodução de outros, anteriores a si.

Os debates em torno do tema foram acalorados. Quase todos queriam expor suas opiniões e impressões a respeito da sua identidade. Os alunos reconheciam, em si, seus 


\section{SEMINÁRIO DE PESQUISA EM CIÊNCIAS HUMANAS - SEPECH \\ Humanidades, Estado e desafios didático-científicos \\ Londrina, 27 a 29 de julho de 2016}

pais, avós e até amigos de sala. Havia discordâncias, afirmações subjetivas, delimitações entre "eu" e "outros", tornando-se inviável ao final, devido à escassez do tempo, a retomada do texto e a condução que o poeta traça a respeito do tema da identidade.

Observou-se, assim, que houve predisposição à sobrecodificação, à apropriação criativa do texto, a partir de experiências prévias, externas à leitura.

\section{CONSIDERAÇÕES FINAIS}

A leitura pode ser compreendida enquanto prática criativa, vinculada à constituição da subjetividade. À formação do leitor, nesse sentido, é imprescindível a vivência com espaços de leitura em que a criatividade esteja em pauta e, assim, enseje sentidos e o próprio engajamento do sujeito com a atividade leitora.

Pelo que pudemos observar nas aplicações da propostas de leitura literária, há, da parte das crianças, uma aceitabilidade muito forte de práticas que possibilitem a sua entrada no universo da literatura a partir da criatividade e da subjetividade.

Podemos dizer que as propostas efetuadas nas escolas foram razoavelmente efetivadas, considerando-se o tempo e o espaço que nos foram cedidos para sua realização. Entretanto, não é desproporcionado afirmar que indiciaram caminhos de leitura e movimentação do impulso criativo das crianças, as quais conseguiram participar, cadenciando a atividade leitora em perguntas e reformulações de conclusões. "A gente é que nem o Frankenstein?", a pergunta persistiu até o fim da conversa na aula dedicada à poesia, e possivelmente após ela, com respostas e argumentações diversas entre os alunos. Nos espaços dados à expressão do vivido antes e do revivido na literatura, os alunos puderam deixar vir à tona elementos de subjetividade e, num evidente entusiasmo, expor-se por intermédio da leitura.

$\mathrm{Na}$ atividade com texto teatral, o fato de ter sido realizada em contexto privilegiado de aprendizagem não sugere a impossibilidade de realizá-la em outros ambientes que não gozem das mesmas condições, mas, sim, a necessidade premente de se repensarem tais espaços, no sentido de promover verdadeira alteração dos cenários para, assim, criar novas expectativas para a formação do leitor e garantir que o direito humano de tornar-se leitor seja efetivado.

A leitura, da forma como vem sendo tratada nos LD do Ciclo 1 de Língua Portuguesa, não tem passado de uma mera reafirmação de um lugar submisso a discursos que não permitem a emergência de sujeitos-leitores, capazes de se contrapor a toda ordem de clichês e de verdades pré-estabelecidas. Trata-se, efetivamente, de um treino de conformação ao que está dado, sem espaços de reflexão, para os quais a criatividade e a subjetividade são elementos fundantes.

A leitura do texto literário, nos moldes como vem sendo levada pelos LD, não promove a vinculação do leitor com as obras e mesmo com o próprio ato da leitura, na medida em que tolhe o que lhe é mais característico: o encontro das subjetividades a partir da experiência impactante do conhecimento do outro e do retorno a si por ressignificações e sobrecodificações desse outro e de si mesmo.

Estabelecer novos modos de ler na escola parece-nos, nesse sentido, uma urgência que deve conduzir a uma formação mais consistente do leitor e a garantia de direitos fundamentais, como o da própria leitura e, em última análise, o direito de ser. 


\section{SEMINÁRIO DE PESQUISA EM CIÊNCIAS HUMANAS - SEPECH \\ Humanidades, Estado e desafios didático-científicos \\ Londrina, 27 a 29 de julho de 2016}

\section{REFERÊNCIAS BIBLIOGRÁFICAS}

ANDERSEN, Hans Christian. Contos e histórias. Tradução de Renata Cordeiro. São Paulo: Landy, 2004.

BARTHES, Roland. "Da leitura". In: BARTHES, Roland. O rumor da língua. Tradução de Mario Laranjeira. São Paulo: Martins Fontes, 2004, p. 30-42.

COLOMER, Teresa. Andar entre livros: a leitura literária na escola. Tradução de Laura Sandroni. São Paulo: Global, 2007.

FREUD, Sigmund. Além do princípio do prazer. Tradução de Christiano Monteiro Oiticica. Rio de Janeiro: Imago, 2003.

INDURSKY, Freda. F. Estudos da linguagem: a leitura sob diferentes olhares teóricos. In: TFOUNI, L.V. (org.). Letramento, escrita e leitura. Campinas: Mercado de Letras, 2010, p. 163-178.

LACAN, Jacques. Seminário, livro 11: os quatro conceitos fundamentais da psicanálise. Texto estabelecido por Jacques-Alan Miller. Tradução M.D. Magno. Rio de Janeiro: Jorge Zahar, 2008.

MACHADO, Maria Clara. Teatro infantil. Rio de Janeiro: Agir, 1967.

PAES, José Paulo. Lé com cré. São Paulo: Ática, 1996.

PETIT, Michele. A arte de ler ou como resistir à adversidade. Tradução de Arthur Bueno e Camila Boldrini. São Paulo: 34, 2009.

WINNICOTT, Donald Woods. O Brincar e a Realidade. Tradução de Jose Octávio de Aguiar Abreu e Vanede Nobre. Rio de Janeiro: Imago, 1975. 